\title{
Standardized method to extract phenolic compounds from Lagerstroemia speciosa L. (Jarul) for enhanced antioxidant activity
}

\author{
Monika Bajpai \\ Department of Chemistry, Indian Academy Degree College-Autonomous, Bangalore- 560043 \\ (Karnataka), India \\ Madhusudan S \\ Department of Biotechnology, Maharani Cluster University, Bangalore-560001 (Karnataka), \\ India

\section{Sibi G*} \\ Department of Biotechnology, Indian Academy Degree College-Autonomous, Bangalore- 560043 \\ (Karnataka), India \\ *Corresponding author. Email: gsibii@gmail.com
}

\section{How to Cite}

Bajpai, M. et al. (2021). Standardized method to extract phenolic compounds from Lagerstroemia speciosa L. (Jarul) for enhanced antioxidant activity. Journal of Applied and Natural Science, 13(3), 1041 - 1047. https://doi.org/10.31018/jans.v13i3.2870

\begin{abstract}
Phenolic compounds contribute to the antioxidant property of plants and the efficient extraction of plant phenolics could enhance its antioxidant potential. Lagerstroemia speciosa (L.) Pers. has been investigated for its pharmacological activities, but comparing its antioxidant activities of phenolics derived from its various parts has a key role in developing natural antioxidants. This study was conducted to standardize the extraction of phenolics from leaves, pods and branches of $L$. speciosa plant, followed by determination of antioxidant activities of their solvent fractions. Phenolic compounds were extracted from the leaves, pods and branches under different parameters such as temperature, $\mathrm{pH}$, type of solvent and volume of the solvent. The extracted phenolic compounds were subjected to solvent fractions and antioxidant assays were performed. Among the various extraction methods tested, the best method was $50 \%$ ethanol $+1 \% \mathrm{HCl}$, refluxing temperature, $100 \mathrm{ml}$ of solvent and 1 hour extraction time. The best solvent fractions were determined as $\mathrm{NaHCO}_{3}+$ ethyl acetate for pods and ethyl acetate alone for leaves and branches with extracted phenolics content of $150.2 \mathrm{mg} / \mathrm{g}, 136.2 \mathrm{mg} / \mathrm{g}$ and $82.9 \mathrm{mg} / \mathrm{g}$, respectively. The chloroform fraction was best among the fractions with maximum ascorbic acid equivalent (ASE) in all the parts of $L$. speciosa tested. Ferrous ion chelating capacity indicated that butanol fraction had the highest chelation and the same was recorded in ferric ion chelating assay with an EC50 value of 28.2. Hydroxyl radical scavenging activity of the fractions indicated that $\mathrm{NaHCO}_{3}+$ EtOAc fraction of pods had potential activity. Thus, the phenolic compounds from $L$. speciosa are excellent sources for future investigation on potent natural antioxidant compounds.
\end{abstract}

Keywords: Banaba, Jarul, Lagerstroemia speciosa, Phenolics, Polyphenols, Antioxidant

\section{INTRODUCTION}

Lagerstroemia speciosa Pers. Jarul or banaba is a medium-sized to large deciduous tree widely distributed in South East-Asian countries, the Philippines and India. Plants with considerable quantities of antioxidants help investigators to identify natural antioxidants in preventing diseases caused by free radicals and reactive oxygen species. Due to its antioxidant activities, great attention has been given to $L$. speciosa (Nurcahyanti et al., 2018). Glycosides, flavones, triterpenes, tannins, corosolic acid, ellagic acid and its derivatives have been isolated from various parts of L. speciosa (Stohs et al., 2012; Tiwary et al., 2017; Chan et al., 2014). L. speciosa is reported to possess several polyphenolic compounds (Choi et al., 2015). Leaves of the plant possess antioxidant and free radical scavenging activities (Unno et al., 1997). Polyphenol from the leaves has many biological activities (Janggyoo et al., 2015; Song et al., 2013a). Flowers are a good source of phenolic compounds with antioxidant activities (Kaisoona et al., 2011; Tiwary et al., 2017) and had demonstrated DPPH scavenging activity when chloroform was used for extraction (Sharmin et al., 2018). Corosolic acid, ellagitannins, ellagic acid from banaba leaves have hypoglycemic activity (Bai et al., 2008; Stohs et al., 
2012; Guo et al., 2020). Leaves of the plant have potential antitumor effects (Mousa et al., 2019; Song et al., 2013b) activity. The other biological activity of the plant includes antimicrobial (Chan et al., 2014), antifibrotic (Prabhu et al., 2010) and analgesic (Gupta et al., 2017) effects.

Phenolic compounds are capable of scavenging free radicals of different origins (Qadir et al., 2017; Moukette et al., 2015; Lobo et al., 2010; Bravo, 1998). Polyphenol content and composition depends on the plant part and processing conditions. Based on the potential biological activities of $L$. speciosa, this study was designed to determine the best methods to extract phenolic compounds from various parts of the plant and determine the effect of different parameters such as temperature, $\mathrm{pH}$, type of solvent, and volume of the solvent. Solvent fractions of $L$. speciosa were prepared and tested for the antioxidant activities of polyphenols under in vitro conditions.

\section{MATERIALS AND METHODS}

\section{Plant materials}

The leaves, pods and branches of $L$. speciosa were collected from agronomical experimental trials at Aurawan Research Center of the Institute and Pantnagar. The samples were shade dried, ground to a fine powder and passed through a sieve (24 mesh).

\section{Selection of best solvent, temperature, time and} volume of extraction

\section{Effect of solvent}

To find out the suitable solvent for extraction of total phenolics, solvents of varying polarity like ethyl acetate, methanol and ethanol in combination with water and acid like hydrochloric acid were selected: $50 \% \mathrm{MeOH}+$ $1 \% \mathrm{HCl}, 3: 1 \mathrm{EtOH} / \mathrm{EtOAc}+0.5 \% \mathrm{HCl}, 75 \% \mathrm{MeOH}, 100 \%$ $\mathrm{MeOH}, 50 \% \mathrm{EtOH}, 50 \% \mathrm{EtOH}+1 \% \mathrm{HCl}, 50 \% \mathrm{MeOH}$, $10 \% \mathrm{MeOH}, 3: 1 \mathrm{EtOH} / \mathrm{EtOAc}$. For this study, $25 \mathrm{mg}$ of plant sample was extracted with $10 \mathrm{ml}$ of abovementioned solvents for 12 hours.

\section{Effect of temperature}

In order to find out the optimum temperature, sample was extracted with the best-selected solvent at room temperature, $50^{\circ} \mathrm{C}, 75^{\circ} \mathrm{C}, 100^{\circ} \mathrm{C}$ in five different conical flasks and the last one was refluxed.

\section{Effect of time of extraction (single extraction)}

The pods, branches and leaves were used for the selection of appropriate time of extraction. For this study, $25 \mathrm{~g}$ of sample was kept for 1, 2, 3 and 24 hours in 100 $\mathrm{ml}$ of the selected solvent at appropriate temperatures optimized in the above studies.

\section{Effect of volume of solvent}

The pods, branches and leaves were used for the selection of the appropriate volume of extraction. For this study, $1 \mathrm{~g}$ of sample was kept for 1 hour in 10, 20, 40, 60,80 and $100 \mathrm{ml}$ of solvent at appropriate temperatures optimized in the above studies.

\section{Total phenolic content (TPC) estimation}

TPC in different extracts was measured with the slightly modified method of Ragazzi and Veronese (1973). In brief, $1 \mathrm{ml}$ plant extract was added with $1 \mathrm{ml}$ of Folin's Reagent $(1 \mathrm{~N})$ and $2 \mathrm{ml}$ of $\mathrm{Na}_{2} \mathrm{CO}_{3}(20 \%)$. The contents were mixed well and kept at room temperature for 30 min and the final volume was made upto $25 \mathrm{ml}$ with distilled water. The absorbance of mixture was measured at $\lambda_{\max } 725 \mathrm{~nm}$ on UV-Vis spectrophotometer. TPC were expressed as gallic acid equivalent (GAE) $\mathrm{mg} / \mathrm{g}$ on a dry weight basis.

\section{Effect of solvent fractions and on antioxidant activi- ty of $L$. speciosa extracts}

After selecting the best solvent and conditions on the basis of their TPC, polyphenols were extracted in the dried and powdered sample $(10 \mathrm{~g})$ by using $50 \mathrm{ml}$ of $50 \%(\mathrm{v} / \mathrm{v})$ aqueous ethanol $+1 \% \mathrm{HCl}$. The mixture was shaken in a rotary shaker at a constant stirring rate at room temperature $\left(25^{\circ} \mathrm{C}\right)$ for $1 \mathrm{~h}$. Solids were separated by filtration by washing them with $50 \%$ methanol/ water. The solvent from the extract was removed under reduced pressure at $150 \mathrm{PSI}$ and $40^{\circ} \mathrm{C}$ in a Buchi Rotavapor. The viscous residue thus obtained is called crude plant extract. The crude extract was redissolved in water and refluxed for 1 hour to convert the esters into the free phenolic acid. The resulting extract (100 $\mathrm{ml}$ ) was partitioned with $50 \mathrm{ml}$ of hexane. The obtained defatted hexane fraction was divided into 5 parts of 20 $\mathrm{ml}$ each and was extracted with ethyl acetate, ether, chloroform and butanol as such and $\mathrm{pH}$ of the remaining $20 \mathrm{ml}$ is brought to $7.0-8.0$ by the addition of $5 \%$ sodium bicarbonate. The ether, chloroform, butanol and both the ethyl acetate and their respective aqueous fractions were washed with $10 \mathrm{ml}$ water and dried on 2 $\mathrm{g}$ of anhydrous sodium sulphate separately for 2 hours, followed by filtration. The solvent was removed under reduced pressure at 50 pounds per square inch (PSI) at $40^{\circ} \mathrm{C}$. The viscous residues thus obtained were analyzed for their antioxidant activities.

\section{Antioxidant activity (AOA)}

$\mathrm{AOA}$ was estimated as described by Emmons and Peterson (1999) by monitoring the coupled autoxidation of b-carotene and linoleic acid. $2 \mathrm{mg}$ of $\beta$-carotene was dissolved in $20 \mathrm{ml}$ of $\mathrm{CHCl}_{3}$ and its $3 \mathrm{ml}$ was added to $40 \mathrm{mg}$ of linoleic acid and $400 \mathrm{mg}$ of Tween 40 . After removing $\mathrm{CHCl}_{3}$ under reduced pressure, $100 \mathrm{ml}$ of 
oxygenated water was added and mixed properly to obtain a stable emulsion. $3 \mathrm{ml}$ aliquots of emulsion were mixed with $40 \mu \mathrm{l}$ of plant extracts and incubated for 1 hour at $50^{\circ} \mathrm{C}$. The absorption $\left(\lambda_{\max } 470 \mathrm{~nm}\right)$ of test mixture was recorded at 0 and after 60 minutes of incubation at $50^{\circ} \mathrm{C}$. The $A O A$ was expressed as per cent of inhibition relative to control after $60 \mathrm{~min}$. Activity of plant extracts was compared with standard curve of butylated hydroxy toluene (BHT) over a concentration range of 0 to $1.4 \mu \mathrm{g}$ in $40 \mu \mathrm{l}$ of sample. Antioxidant activity was expressed as percent inhibition relative to control after a 60 minutes incubation period and calculated by the following formula:

$$
\mathrm{AOA}=\frac{100 \times(\mathrm{DRc}-\mathrm{DRs})}{\mathrm{DRc}}
$$

Where: $\mathrm{DR}_{\mathrm{C}}=$ rate of degradation of control $=\ln (\mathrm{a} /$ b) $/ 60$

$\mathrm{DR}_{\mathrm{S}}=$ degradation rate of sample $=\ln (\mathrm{a} / \mathrm{b}) / 60$

$a$ and $b=$ absorbance at 0 and 60 minutes.

\section{Free radical scavenging activity (FRSA) and reduc-} ing capacity

$10 \mathrm{mg}$ of plant extract residue was dissolved in $10 \mathrm{ml}$ $\mathrm{MeOH}$ and its $0.1 \mathrm{ml}$ was added to $2.9 \mathrm{ml}$ freshly prepared 1,1-diphenyl-2-picryl- hydrazil (DPPH) solution (6 $x 10^{-5} \mathrm{M}$ in $\mathrm{MeOH}$ ). The absorbance was recorded at $\lambda_{\max } 517 \mathrm{~nm}$ after 1 hour of incubation. The FRSA was calculated according to the method of Yen and Duh (1994). The inhibitory concentration $\left(I_{50}\right)$, efficiency concentration $\left(\mathrm{EC}_{50}\right)$ and anti-radical power (ARP) were estimated and calculated as described by Kroyer (2004). Reducing capacity of plant extracts $(1 \mathrm{mg} / \mathrm{ml}$ in $\mathrm{MeOH}$ ) was determined using a modified ferric reducing - antioxidant power assay and quercetin as reference standard. 100, 200, 300, 400 and 500 $\mu$ l aliquots of samples were maintained to $1 \mathrm{ml}$ with $\mathrm{MeOH}$, followed by the addition of $2.5 \mathrm{ml}$ phosphate buffer $(\mathrm{pH}$ 6.6 ) and $2.5 \mathrm{ml}$ of $1 \% \mathrm{w} / \mathrm{v}$ potassium ferric cyanide in each. The reaction mixtures thus obtained were incubated at $50^{\circ} \mathrm{C}$ in water bath for $20 \mathrm{~min}$. After incubation, reaction was terminated by the addition of $2.5 \mathrm{ml}$ of $10 \% \mathrm{w} / \mathrm{v}$ trichloroacetic acid (TCA) solution. $2.5 \mathrm{ml}$ of above solution from each reaction was diluted with equal amount of deionized water. $0.5 \mathrm{ml}$ of $\mathrm{FeCl}_{3}(0.1 \%$ w/v) was added in each and absorbance $\left(\lambda_{\max } 700 \mathrm{~nm}\right)$ was recorded after 10 min. Reducing power was expressed as ascorbic acid equivalent $(1 \mathrm{mM}=1 \mathrm{ASE})$. The ASE/ml value is inversely proportional to reducing power.

\section{Ferrous ion chelating capacity test}

$10 \mathrm{mg}$ of plant extract residue was dissolved in $10 \mathrm{ml}$ $\mathrm{MeOH}$ and its ferrous ion chelating capacity test was determined by the method of Decker and Welch (1990). Aliquots $(100,200,300,400$ and $500 \mu l)$ of samples were maintained to $1 \mathrm{ml}$ with $\mathrm{MeOH}$, followed by the addition of $0.1 \mathrm{ml}$ of $2 \mathrm{mM}$ ferrous chloride, $0.2 \mathrm{ml}$ of 5 $\mathrm{mM}$ ferrozine (3-(2-pyridyl)-5,6-bis- (4-phenylsulfonic acid)-1,2,4-triazine) and $3.7 \mathrm{ml}$ methanol. The reaction mixture was kept at room temperature for 10 minutes and absorbance was measured at $\lambda_{\max } 562 \mathrm{~nm}$. A lower absorbance indicates a higher ferrous ion chelating capacity.

\section{Ferric thiocyanate Assay}

Ferric thiocyanate assay was performed by mixing 400 $\mu \mathrm{l}$ of plant extract $(0.01$ to $2 \mathrm{mg} / \mathrm{ml}), 200 \mu \mathrm{l}$ of diluted linoleic acid $(25 \mathrm{mg} / \mathrm{ml}, 99 \%$ ethanol) and $400 \mu \mathrm{l}$ of 50 $\mathrm{mM}$ phosphate buffer ( $\mathrm{pH}$ 7.4) followed by incubation at $40^{\circ} \mathrm{Cfor} 15 \mathrm{~min}$. A $100 \mu \mathrm{l}$ aliquot was then mixed with a reaction mixture containing $3 \mathrm{ml}$ of $70 \% \mathrm{EtOH}$, $100 \mu \mathrm{l}$ of ammonium thiocyanate $(300 \mathrm{mg} / \mathrm{ml}$ dry weight) and $100 \mu \mathrm{l}$ of ferrous sulphate. The developed red color was measured at $\lambda_{\max } 500 \mathrm{~nm}$ (Tsuda et al., 1993).

\section{Scavenging effect on hydroxyl radicals}

Hydroxyl radical scavenging activity was measured according to the method of Halliwell et al., (1987). Reaction mixture consisting $500 \mu \mathrm{l}$ of sample at different concentrations ranging from 0.05 to $1.25 \mathrm{mg} / \mathrm{ml}$ and $100 \mu \mathrm{l}$ each of $2 \mathrm{mM} \mathrm{H}_{2} \mathrm{O}_{2}, 2 \mathrm{mM}$ ferric chloride, 0.05 $\mathrm{mM}$ ascorbate, $6 \mathrm{mM}$ deoxyribose and $0.05 \mathrm{mM}$ EDTA prepared in $0.02 \mathrm{M}$ phosphate buffer $(\mathrm{pH} 7.4)$ was incubated at $37^{\circ} \mathrm{C}$ for 60 minutes. After addition of $1 \mathrm{ml}$ of $2.8 \%(\mathrm{w} / \mathrm{v})$ trichloroacetic acid and $1 \mathrm{ml}$ of $1 \%(\mathrm{w} / \mathrm{w})$ 2-thiobarbituric acid, the reaction mixture was further heated in a boiling water bath for 15 minutes. The colour developed was measured at $\lambda_{\max } 532 \mathrm{~nm}$ against a blank containing phosphate buffer only. Hydroxyl radical scavenging activity was measured with the inhibition of deoxyribose oxidation and the hydroxyl radical scavenging activity was calculated as below;

$\%$ scavenging $=\left[A_{0}-\left(A_{1}-A_{2}\right] \times 100 / A_{0} \ldots\right.$ Eq. 2

Where, $A_{0}$ is the absorbance of the control. $A_{1}$ is the absorbance of sample with 2-deoxy-D-ribose. $A_{2}$ is the absorbance of the sample without 2-deoxy-D-ribose.

\section{RESULTS AND DISCUSSION}

Various solvents at different concentrations and combinations used to extract total phenolics from different parts of L. speciosa showed that leaves of the plant were rich with phenolics than the pods and branches. Among the solvents tested, $50 \% \mathrm{EtOH}+1 \% \mathrm{HCl}$ had recovered maximum phenolics from the $L$. speciosa parts (Fig.1)

The results on the effect of temperature on the extraction of phenolics revealed that higher temperatures lead to the maximum recovery of phenolics (Fig. 2). However, refluxing the plant extract resulted in better 
extraction of phenolics from the leaves of the plant. Similarly, the higher the volume of solvent used, the better was the extraction of the phenolics (Fig. 3). Extraction of phenolic with best solvent combination for 1 hour period resulted in maximum phenolic as expressed in gallic acid equivalents $(\mathrm{mg} / \mathrm{g})$. Total phenolics were also higher in overnight extraction, but in this study, 1 hour extraction was considered the optimal extraction time for $L$. speciosa (Fig. 4).

Organic solvents are employed to extract the free and soluble conjugate phenolic acids, whereas acid, alkali treatment releases bound phenolics (Krygier et al., 1982). Among the solvent fractions prepared using ethanol, ether, chloroform, butanol and ethyl acetate + $\mathrm{NaHCO}_{3}$ as alkali treatment to release bound phenolics from $L$. speciosa, ethyl acetate $+\mathrm{NaHCO}_{3}$ treatment

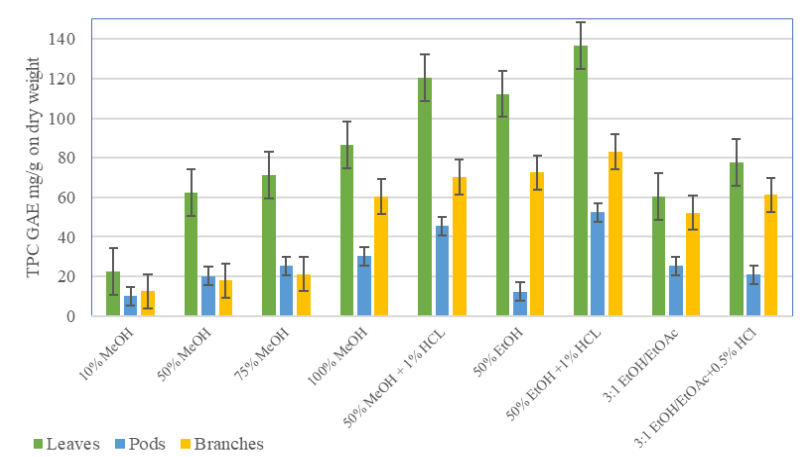

Fig. 1. Effect of time on total phenolics extraction.

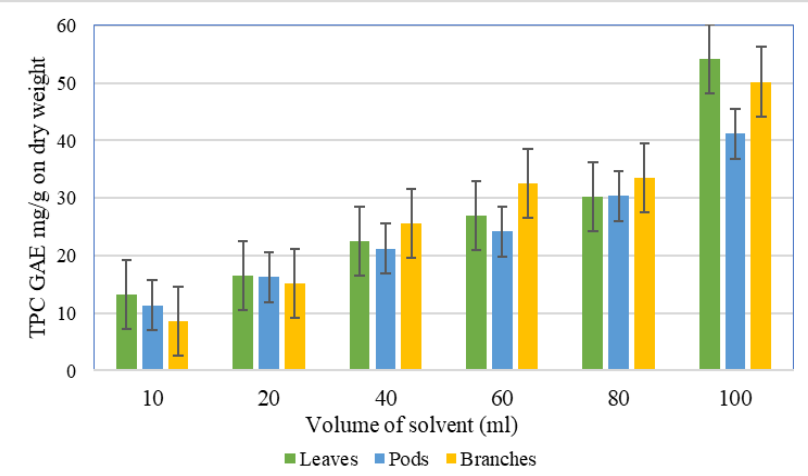

Fig. 3. Effect of volume of solvent on total phenolics extraction.

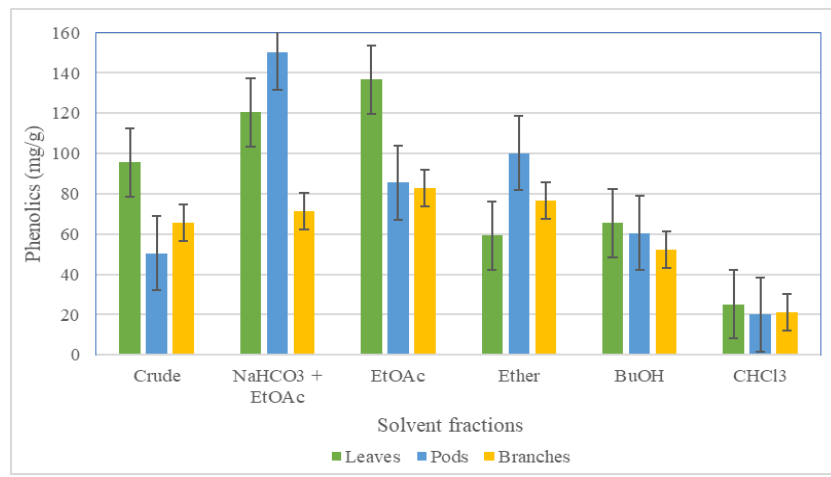

Fig. 5. Phenolic contents in solvent fractions. released maximum phenolics $(150.2 \mathrm{mg} / \mathrm{g})$ from pods, whereas ethyl acetate fraction resulted in the maximum release of phenolics from leaves $(136.2 \mathrm{mg} / \mathrm{g})$ and branches (82.9 mg/g) (Fig.5). Antioxidant activities of solvent fractions indicated that $L$. speciosa exhibited the suitable solvent fraction with highest antioxidant activity. Total antioxidant activity was highest in ethyl acetate fraction of leaves and branches (85.6\%) followed by ethyl acetate $+\mathrm{NaHCO}_{3}$ fraction of pods $(82.3 \%)$ as depicted in Fig.6.

FRSA assay of different solvent fractions revealed that chloroform fraction was best among the fractions with maximum ascorbic acid equivalent (ASE) in all the parts of $L$. speciosa tested (Fig.7a-7d). Ferrous ion chelating capacity of $L$. speciosa indicated that butanol fraction had highest chelation capacity followed by chloroform

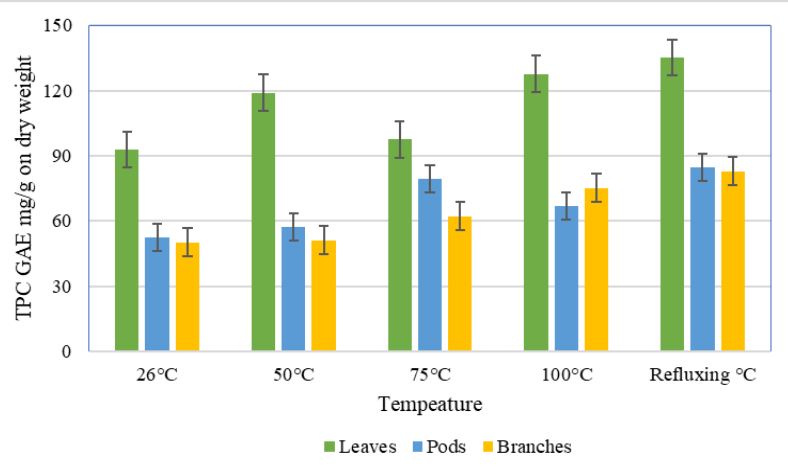

Fig. 2. Effect of temperature on total phenolics extraction.

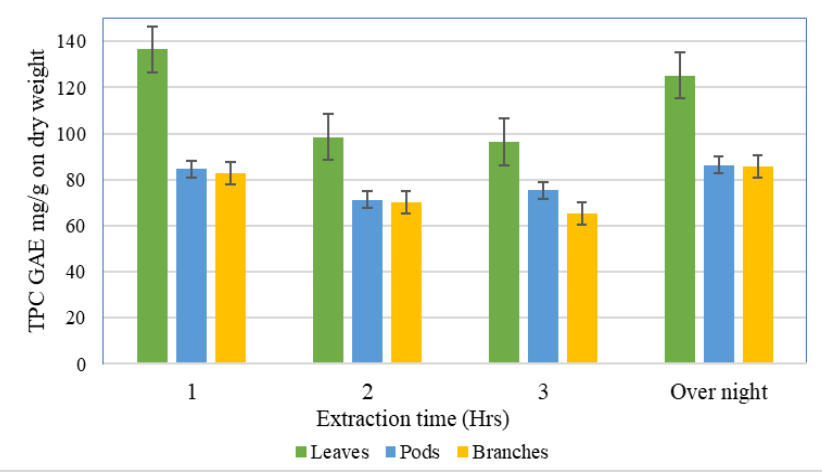

Fig. 4. Effect of extraction time on total phenolics extraction.

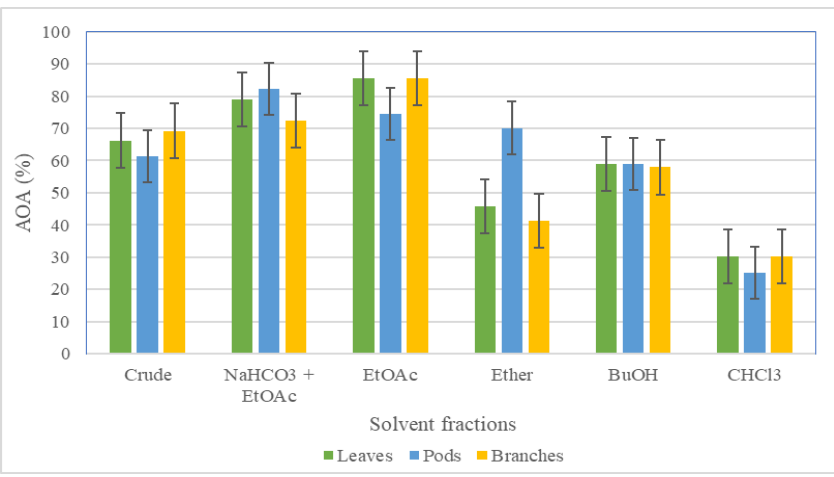

Fig. 6. Total antioxidant activity of solvent fractions. 
fraction (Fig. 8). Butanol fraction from branches of the plant recorded the highest ferrous ion chelating capacity with $I_{50}$ value of 0.65 . Similar results were also obtained for ferric ion chelating assay where butanol fraction of branches exhibited $\mathrm{EC}_{50}$ value of 28.2 followed by chloroform fraction of pods with $\mathrm{EC}_{50}$ value of 26.5 (Fig. 9).

Hydroxyl radical scavenging activity of the fractions indicated that $\mathrm{NaHCO}_{3}+$ EtOAc fraction of pods had potential activity followed by ethyl acetate fraction of branches.

Supplementation of antioxidants from plant origin helps in controlling the reactive oxygen species-mediated damage with minimal side effects (Dina et al., 2009). Plants are proven to be a good source of antioxidants. The nature of antioxidant activity depends on the plant part. Phenolic compounds are primarily responsible for the antioxidant activities of plants and the extraction of plant phenolics is influenced by various factors such as type of solvent and extraction conditions. Flower extract of $L$. speciosa exhibited higher antioxidant activities due to their phenolic compounds (Tiwary et al., 2017) and in this present study, antioxidant activities of leaves, pods and branches of $L$. speciosa were observed indicating the antioxidant properties of the apical parts of the plant.

Leaves extract of the plant alleviates oxidative stress through decreased non-enzymatic and enzymatic antioxidants (Mousa et al., 2019). The leaves were protective against oxidative stress (Song et al., 2013). Aerial

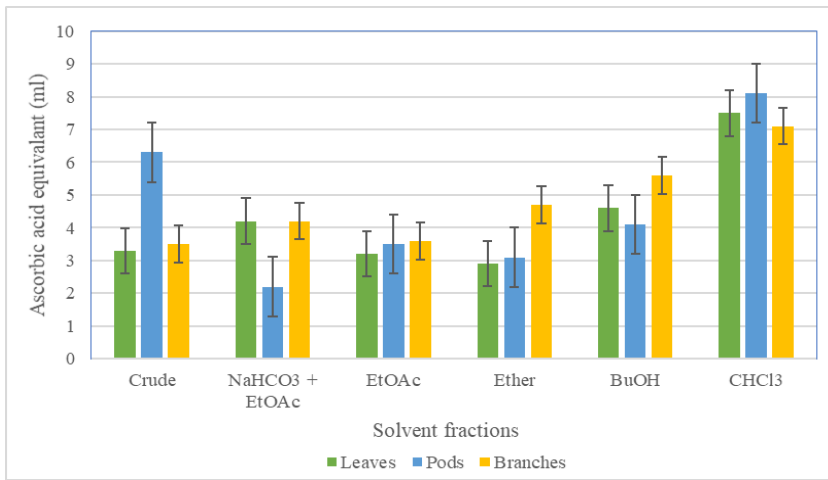

Fig. 7a. FRSA activity of solvent fractions.

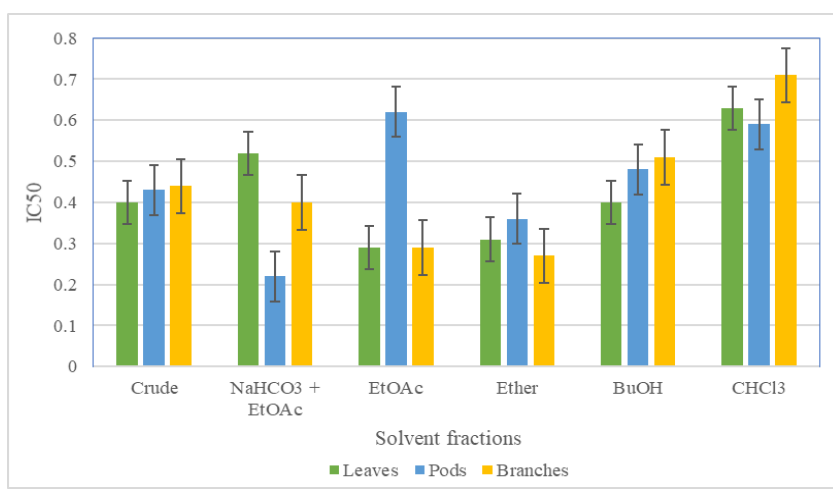

Fig. 7c. Efficiency concentration $\left(E C_{50}\right)$ of solvent fractions. parts of the plant have inhibitory activities against nitric oxide production (Choi et al., 2015). In another study, leaves of this plant demonstrated significant antioxidant activities in vitro (Pareek et al., 2010). The major chemical constituents of the leaves are ellagic acid, ellagitannins, caffeic acid and corosolic acid (Bai et al., 2008). Although seeds, leaves and flowers of $L$. speciosa were studied individually for their antioxidant activity (Junaid et al., 2013; Saumya and Basha, 2011; Pavithra et al., 2013), no report exists on comparing antioxidant activities of phenolic compounds from leaves, pods and branches of this plant. Therefore, this study determined the best extraction methods to obtain phenolic compounds from various parts of this plant and examined their antioxidant activities.

To understand the antioxidant activities of its phenolic compounds from solvent fractions, various experiments on in vitro assays indicated varying results. Among the various extraction methods tested, the best methods were $50 \%$ ethanol $+1 \% \mathrm{HCl}$, refluxing temperature, 100 $\mathrm{ml}$ of solvent and 1 hour extraction time. The results revealed the presence of the high amount of phenolic compounds in leaves, pods and branches of L. speciosa. Similarly, the best solvent fractions were determined as $\mathrm{NaHCO}_{3}+$ ethyl acetate for pods and ethyl acetate alone for leaves and branches. The present study revealed in general that solvent fractions were proven to exhibit higher antioxidant activities than the crude extract. Sharmin et al., (2008) used the solvent fractions of the flowers of $L$. speciosa and the chloro-

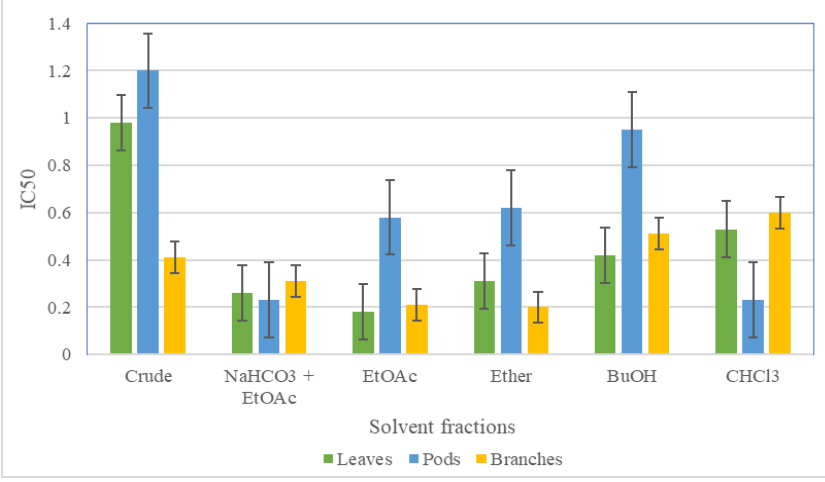

Fig $7 \mathrm{~b}$. Inhibitory concentration $\left(I C_{50}\right)$ of solvent fractions.

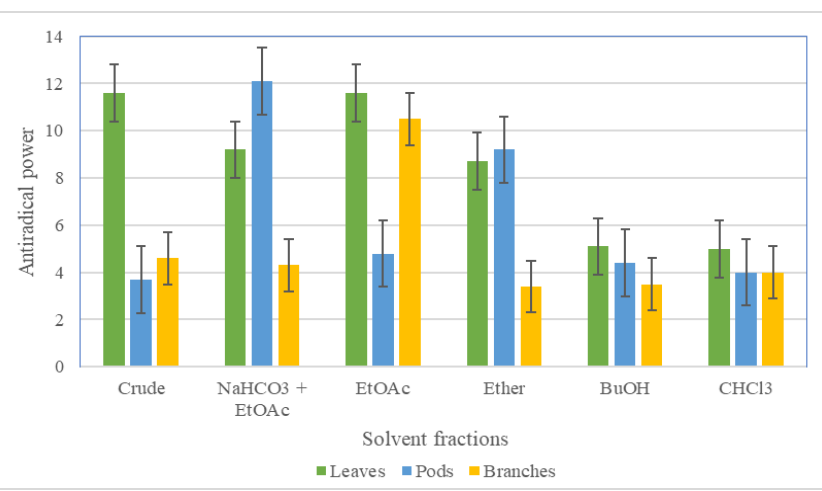

Fig. 7d. Antiradical power of solvent fractions. 


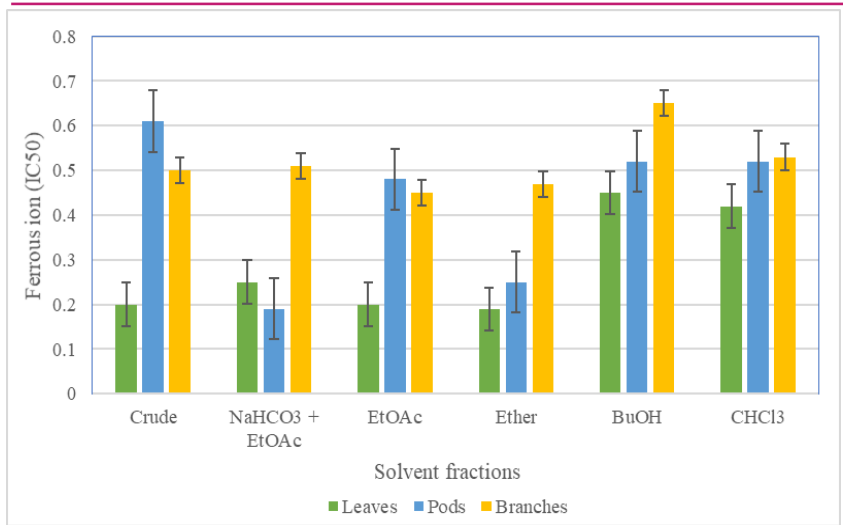

Fig. 8. Ferrous ion chelation activity of solvent fractions.

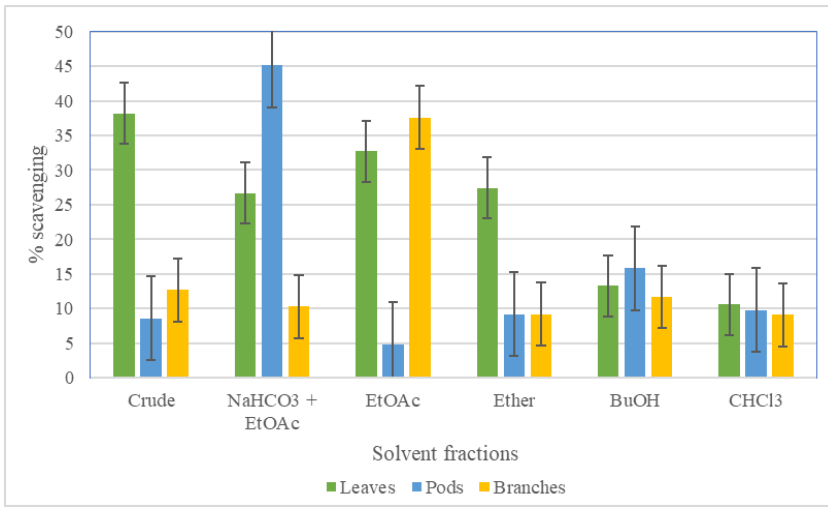

Fig. 10. Hydroxyl radical scavenging activity of solvent fractions.

form fraction demonstrated the highest antioxidant activity in terms of DPPH free radical scavenging. Similarly, subsequent solvent extracts were investigated for its antioxidant activities in an earlier study (Priya et al., 2008). Based on the findings, it is clear that solvent fractions of $L$. speciosa leaves, pods and branches are better choice in terms of antioxidant activities rather than crude extract.

\section{Conclusion}

This study revealed the presence of higher amounts of phenolic compounds in leaves than the pods and branches of $L$. speciosa which can function as antioxidants. Standardized of extraction method using best solvent, volume of solvent, optimal temperature and extraction time to extract phenolics from various parts of the plant is reported in this study and extraction using $50 \%$ ethanol $+1 \% \mathrm{HCl}$ has led to enhanced antioxidant activity of the plant. In conclusion, it can be said that $L$. speciosa is an excellent source of antioxidants and identification of phenolic compounds is necessary for its further use as potent antioxidant source.

\section{Conflict of interest}

The authors declare that they have no conflict of interest.

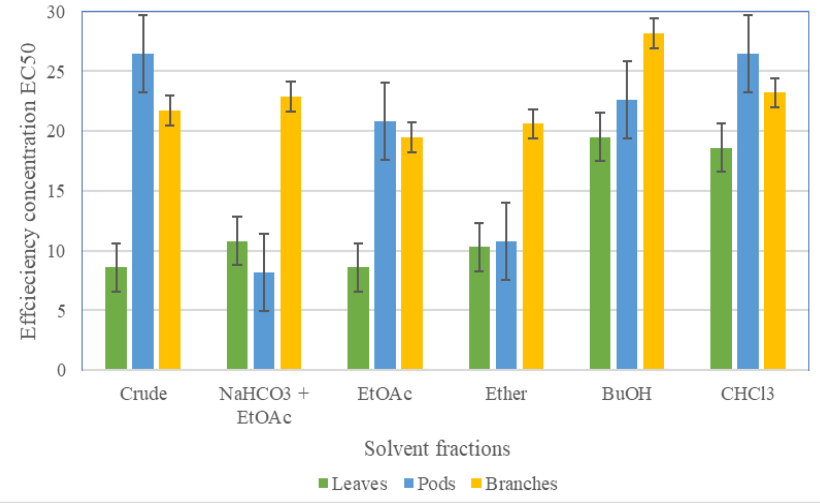

Fig. 9. Ferric ion chelation activity of solvent fractions.

\section{REFERENCES}

1. Bai, N., He, K., Roller, M., Zheng, B., Chen, X., Shao, Z., Peng, T. \& Zheng, Q. (2008). Active compounds from Lagerstroemia speciosa, insulin-like glucose uptakestimulatory/inhibitory and adipocyte differentiationinhibitory activities in 3T3-L1 cells. Journal of Agricultural and Food Chemistry. 56, 11668-11674. DOI: 10.1021/ jf802152z

2. Bravo, L. (1998). Polyphenols: chemistry, dietary sources, metabolism, and nutritional significance. Nutrition Reviews. 56, 317-333. DOI: 10.1111/j.1753-4887.1998.tb016 70.x

3. Chan, E.W.C., Tan, L.N. \& Wong, S.K. (2014). Phytochemistry and pharmacology of Lagerstroemia speciosa: a natural remedy for diabetes. International Journal of Herbal Medicine. 2, 100-105.

4. Choi, J., Cho, J.Y., Choi, S.J., Jeon, H., Kim, Y.D., Htwe, K.M., Chin, Y.W., Lee, W.S., Kim, J., \& Yoon, K.D. (2015). Two new phenolic glucosides from Lagerstroemia speciosa. Molecules (Basel, Switzerland). 20, 4483-4491. DOI: $10.3390 /$ molecules20034483

5. Decker, E.A., \& Welch, B. (1990). Role of ferritin as a lipid oxidation catalyst in muscle food. Journal of Agricultural and Food Chemistry. 38, 674-677. DOI: 10.1021/jf0009 $3 \mathrm{a} 019$

6. Dina, A., Nassima, C., Meriem, B., Karima, A., Hakima, L., \& Hania, B. (2009). Antioxidant capacity and phenol content of selected Algerian medicinal plants. Food Chemistry. 112, 303-309. DOI: 10.1016/j.foodchem.2008.05.077

7. Emmons, C.L., \& Peterson, D.M. (1999). Antioxidant activity and phenolic contents of oats, groats and hulls. Cereal Chemistry. 76, 902-906. DOI: 10.1094/CCHEM.1999.7 6.6.902

8. Guo, S., Ren, X., He, K., Chen, X., Zhang, S., Roller, M., Zheng, B., Zheng, Q., Ho, C.T., \& Bai, N. (2020). The antidiabetic effect of eight Lagerstroemia speciosa leaf extracts based on the contents of ellagitannins and ellagic acid derivatives. Food and Function. 11, 1560-1571. DOI: 10.1039/c9fo03091c

9. Gupta, A., Agrawal, V.K., \& Rao, C.V. (2017). Exploration of analgesic and anti-inflammatory potential of Lagerstro emia speciosa. Journal of Applied and Pharmaceutical Science. 7, 156-161. DOI:10.7324/JAPS.2017.70221

10. Halliwell, B., Gutteridge, J.M.C., \& Aruoma, O.I. (1987). The deoxyribose method: a simple 'test tube' assay for 
determination of rate constants for reaction of hydroxyl radicals. Analytical Biochemistry, 165, 215-219. DOI: 10.1016/0003-2697(87)90222-3

11. Janggyoo, C., Jae, C., Soo, C., Heejin, J., Young, K., Khin, H., Young, C., Woo, L., Jinwoong, K., \& Kee, Y. (2015). Two new phenolic glucosides from Lagerstroemia speciosa, Molecules., 20, 4483-4491. DOI: 10.3390/ molecules20034483

12. Junaid, S., Rakesh, K.N., Dileep, N., Poornima, G., Kekuda, P.T.R., \& Mukunda, S. (2013). Total phenolic content and antioxidant activity of seed extract of Lagerstroemia speciosa. L. Chemical Science Transactions, 2, 75-80. DOI: $10.7598 /$ cst2012.310

13. Kaisoona, O., Siriamornpuna, S., Weerapreeyakulb, N., \& Meesoc, N. (2011). Phenolic compounds and antioxidant activities of edible flowers from Thailand. Journal of Functional Foods. 3, 88-99. DOI: 10.1016/j.jff.2011.03.002

14. Kroyer, G.T. (2004). Red clover extract as antioxidant active and functional food ingredient. Innovative Food Science and Emerging Technologies. 5, 101-105. DOI: 10.1016/S1466-8564(03)00040-7

15. Krygier, K., Sosulski, F., \& Hodge, L. (1982). Free, esterified, and insoluble bound phenolic acids. 1. Extraction and purification procedure. Journal of Agricultural and Food Chemistry. 30, 330-334. DOI: 10.1021/jf00110a028

16. Lobo, V., Patil, A., Phatak, A., \& Chandra, N. (2010). Free radicals, antioxidants and functional foods: Impact on human health. Pharmacognosy reviews, 4, 118-126. DOI: 10.4103/0973-7847.70902

17. Moukette, B.M., Pieme, C.A., Njimou, J.R., Biapa C.P.N., Marco, B., \& Ngogang, J.Y. (2015). In vitro antioxidant properties, free radicals scavenging activities of extracts and polyphenol composition of a non-timber forest product used as spice: Monodora myristica. Biological Research, 48, DOI: 10.1186/s40659-015-0003-1

18. Mousa, A.M., El-Sammad, N.M., Abdel-Halim, A.H., Anwar, N., Khalil, W.K.B., Nawwar, M., Hashim, A.N., Elsayed, E.A., \& Hassan, S.K. (2019). Lagerstroemia speciosa (L.) Pers leaf extract attenuates lung tumorigenesis via alleviating oxidative stress, inflammation and apoptosis. Biomolecules, 9, 871. DOI: 10.3390/biom9120871

19. Nurcahyanti, A.D.R., Arieselia, Z., Kurniawan, S.V., Sofyan, F., \& Wink, M. (2018). Revisiting bungur (Lagerstroemia speciosa) from Indonesia as an antidiabetic agent, its mode of action, and phylogenetic position. Pharmacognosy Reviews, 12, 40-45. DOI: 10.4103/ phrev.phrev_20_17

20. Pareek, A., Suthar, M., Rathore, G. S., Bansal, V., \& Kumawat, T. (2010). In vitro antioxidant studies of Lagerstroemia speciosa leaves. Pharmacognosy Journal, 2, 357360. DOI: 10.1016/s0975-3575(10)80109-9

21. Pavithra, G.M., Siddiqua, S., Naik, A.S., Prashith, K.T.R., \& Vinayaka, K.S. (2013). Antioxidant and antimicrobial activity of flowers of Wendlandia thyrsoidea, Olea dioica, Lagerstroemia speciosa and Bombax malabaricum. Journal of Applied and Pharmaceutical Science, 3, 114-120. DOI: 10.7324/JAPS.2013.3619

22. Prabhu, V.V., Chidambaranathan N., Nalini G., Venkataraman, S., Jayaprakash, S., \& Nagarajan, M. (2010). Eval- uation of anti-fibrotic effect of Lagerstroemia speciosa $\mathrm{L}$ pers. on carbon tetra chloride induced liver fibrosis. Current Pharma Research, 1, 56-68. DOI: 10.33786/ JCPR.2010.V01I01.003

23. Priya, T.T., Sabu, M.C., \& Jolly, C.I. (2008). Free radical scavenging and anti-inflammatory properties of Lagerstroemia speciosa (L). Inflammopharmacology. 16, 182-187. DOI: $10.1007 / \mathrm{s} 10787-008-7002-6$

24. Qadir, M.A., Shahzadi, S.K., Bashir, A., Munir, A., \& Shahzad, S. (2017). Evaluation of phenolic compounds and antioxidant and antimicrobial activities of some common herbs. International Journal of Analytical Chemistry. Article ID 3475738, 6 pages, 2017. DOI: 10.1155/2017/3475 738

25. Ragazzi, E., \& Veronese, G. (1973). Quantitative analysis of phenolic compounds after thin layer chromatographic separation. Journal of Chromatography. 77, 369-375. DOI: 10.1016/s0021-9673(00)92204-0

26. Saumya, S.M., \& Basha, P.M. (2011). Antioxidant effect of Lagerstroemia speciosa Pers (banaba) leaf extract in streptozotocin-induced diabetic mice. Indian Journal of Experimental Biology. 49, 125-131.

27. Sharmin, T., Rahman, M. S., \& Mohammadi, H. (2018). Investigation of biological activities of the flowers of Lagerstroemia speciosa, the Jarul flower of Bangladesh. BMC Complementary and Alternative Medicine, 18, 231. DOI: 10.1186/s12906-018-2286-6

28. Song, J.H., Park, K.S., Kwon, D.H., \& Choi, H.J. (2013a). Antihuman rhinovirus 2 activity and mode of action of quercetin-7-glucoside from Lagerstroemia speciosa, Journal of Medicinal Food, 16, 274-279. DOI: 10.1089/ jmf.2012.2290

29. Song, J.L., Zhao, X., Wang, Q., \& Zhang, T. (2013b). Protective effects of Lagerstroemia speciosa on 3morpholinosydnonimine (SIN-1)-induced oxidative stress in HIT-T15 pancreatic $\beta$ cells. Molecular Medicine Reports, 7, 1607-1612. DOI: 10.3892/mmr.2013.1396

30. Stohs, S.J., Miller, H., \& Kaats, G.R. (2012). A review of the efficacy and safety of Banaba (Lagerstroemia speciosa L.) and corosolic acid. Phytotherapy Research, 26, 317-324. DOI: 10.1002/ptr.3664

31. Tiwary, B.K., Dutta, S., Dey, P., Hossain, M., Kumar, A., Bihani, S., Nanda, A.K., Chaudhuri, T.K., \& Chakraborty, R. (2017). Radical scavenging activities of Lagerstroemia speciosa (L.) Pers. petal extracts and its hepato-protection in $\mathrm{CCl}_{4}$-intoxicated mice. BMC Complementary and Alternative Medicine, 17, 55. DOI: 10.1186/s12906-016-1495-0

32. Tsuda, T., Osawa, T., Nakayama, T., Kawakishi, S., \& Ohshima, K. (1993). Antioxidant activity of pea bean (Phaseolus vulgaris L.) extract. Journal of the American Oil Chemists Society, 70, 909-913. DOI: 10.1007/BF02 545353

33. Unno, T., Sakane, I., Masumizu, T., Kohno, M., \& Kakuda, T. (1997). Antioxidative activity of water extracts of Lagerstroemia speciosa leaves. Bioscience, Biotechnology and Biochemistry, 61, 1772-1774. DOI: 10.1271/bbb.61.1772

34. Yen, G.C., \& Duh, P.D. (1994). Scavenging effect of methanolic extracts of peanut hulls on free radical and active oxygen. Journal of Agricultural and Food Chemistry, 42, 629-632. DOI: 10.1021/jf00039a005 